\title{
PALLIDOTOMY IN PARKINSONIAN DISEASE: THE RENAISSANCE
}

\author{
Aurangzeb Kalhoro ${ }^{a}$ Abdul Basit Sattar ${ }^{b}$, Abdul Sattar M. Hashimc ${ }^{c}$ Abid Saleem ${ }^{d}$ \\ ${ }^{a}$ Assistant Professor of Neurosurgery JMDC Karachi \& Consultant Neurosurgeon Neuro Spinal \& \\ Cancer Care Institute, Karachi.

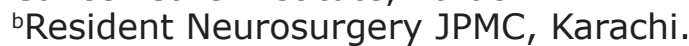 \\ ${ }^{\mathrm{C} E x}$ Prof JPMC \& Medical Director Neurosurgery Spinal \& Cancer Care Institute. \\ dDirector Gamaknife Radiosurgery Neurospinal Cancer Care Institute Karachi.
}

\section{ABSTRACT:}

BACKGROUND \& OBJECTIVE: To assess the results of pallidotomy in Parkinson's disease, and its effect on improving the lifestyle of the patients and cost-effectiveness.

METHODOLOGY: A descriptive study was conducted at Neuro-Spinal \& Cancer Care Institute, Karachi from June 2014 to January 2020. Patients who were known case of Parkinson's disease refractory to medication and developed side effects to medication were included in the study and patients withprevious brain surgery, associated brain disorders like Alzheimer's disease, basal ganglia lesion, brain trauma were excluded. All patients were treated by pallidotomy on the contralateral side. The significance of the difference between groups to compare between the pre-op or post-op treatments was calculated through non-parametric assessment Kruskal-Wallis tests.

RESULTS: The mean age of the patients was around 57 years. There were $34(81 \%)$ male and $8(19 \%)$ female patients' Maximum number of patients who were more than 45 years, were having a left-sided proportion. More male patients were having a left-sided proportion as compared to female patients. The majority of patients (57.5\%) were having dyskinesia as q primary symptom. A significant difference ( $p$-value $<0.001$ ) existed in pre \& post-operative UPDRS-III scores. A significant difference ( $p$-value $<0.001$ ) also existed between on \& off medications UPDRS- III (pre-op/post-op) scores.

CONCLUSION: The result of pallidotomy is promising especially for unilateral pallidotomy to minimize the risk of cognition and speech disorder and long-term follow-up is needed to prove the statement further. Currently, pallidotomy is associated with minimal complications, more effective, and improving the quality of life of Parkinsonian patients.

KEYWORDS: Parkinsonian disease, Pallidotomy, Dyskinesia, Levodopa.

How to cite this:

doi: https://doi.org/10.37723/jumdc.v12i2.535

Kalhoro A, Sattar AB, Hashim ASM, Saleem A.PALLIDOTOMY IN PARKINSONIAN DISEASE: THE RENAISSANCE.jumdc. 2021;12(2):85-91.

doi: https://doi.org/10.37723/jumdc.v12i2.535

This is an Open Access article distributed under the terms of the Creative Commons Attribution License (http://creativecommons.org/licenses/by/4.0), which permits unrestricted use, distribution, and reproduction in any medium provided the original work is properly cited. 


\section{INTRODUCTION:}

Parkinson's disease (PD)is a neurodegenerative disorder which is characterized by the developing loss of striatal dopaminergic function ${ }^{[1]}$. The prevalence of Parkinson's disease in the population is $1-4 \%$ especially above the age of 60 , it affects $1-2 \%$ population at any given frame time $^{[2,3]}$. PD hasthetriad of motor symptoms consist of rigidity, bradykinesia and tremor, additional to that it has motor and non-motor associated characteristics. The disease onset is in late age most likely 65 to 70 years but it can also be in a young age of 40 years which is seen in $5 \%$ cases in given population plus early onset has some genetic association ${ }^{[3]}$.

Currently, PD is presented as a challenge because its prevalence in the world's mostdeveloped and populous country has been predicted to be more than double between the years 2005 and 2030 . These estimates may increase depending on the contribution fromenvironmental exposures ${ }^{[4]}$. Pharmacotherapy related problems which were first reported by L. Laitinen had well-known factor which has led to its renaissance, is the druginduced dyskinesia and motor fluctuations plus other complications. These side effects are caused by prolonged pharmacotherapy with levodopa for at least 3 to 5 years, these symptomsbecome solelydisadaptation factor hideous to the daily activity of the patient. Stereotactic neurosurgery for PD was introduced in 1946 that was classical pallidotomy, was done anterodorsal but in 1950, L. Leksell used pallidotomy bychoosing the target point to the Globus Pallidum internus (GPi) posteroventral approach, this procedure gained popularity as posteroventral pallidotomy (PVP). This procedure had a positive impression on rigidity, bradykinesia, but limited effect on the tremor ${ }^{[5,6]}$.

Stereotactic lesioning has been established as an efficacious and safe surgical option for patients with Parkinson's disease subjected to control levodopa-induced dyskinesia with some risk of speech alterations, weakness, dysarthria and visual field deficits. While other minimally invasive techniques are deep brain stimulation, radiofrequency ablations, focused ultrasound, and radio surgical approaches are also available, but these options are very expensive $[7,8,9]$. Unified Parkinson disease rating scale was used to assess the pre- and post-surgical state in different studies $[5,10]$. The following study was done toassessthe effects of the pallidotomy on patients with PD, who were kept for long time on medical therapy or medical treatment was not effective to control diseasesymptoms. In Pakistan we have limited data regarding surgical option, people usually take it as untreatable surgically, and multiple surgical options are expensive and not affordable in developing countries, although pallidotomy isa safe, less expensive and effective treatment. Through this article, we aimed to increased awareness regarding this effective treatment option of this high prevalence of the chronic disease.

\section{Corresponding Author:}

Dr Aurangzeb Kalhoro

Consultant Neurosurgeon Neuro Spinal \&

Cancer Care Institute, Karachi.

Email:draurangzebkalhoro@gmail.com

\section{METHODOLOGY:}

This descriptive a cross-sectional, prospective study. The study was performed at Neuro-Spinal \& Cancer Care Institute, Karachi from June 2014 to January 2020. With permission from the ethical committee of the hospital, informed consent for the surgical procedure was taken. It was nonprobability consecutive sampling, and total 42 patients were selected based on inclusion criteria of our study, admitted via OPD.

\section{Selection Criteria:}

Inclusion criteria were the patient of any gender who were known case of the parkinsonian disease initially responded to medication, lately developed refractory to medication or developed severe side effects to medication, psychologically stable patients and exclusion criteria are previously operated, associated with secondary brain disorders like Alzheimer's disease, basal ganglia lesion, history of stroke, brain infarction, brain trauma.

\section{Patients' Data:}

Patient's diagnosis was based on the assessment by the experienced neurologist,psychiatrist 
and neurosurgeon and relevant history, clinical examination, CT scan brain and MRI brain plus investigations like ECG, LFT, CBC, RFTs, X-ray chest and blood sugar level, were done for the surgical protocol.Patient clinical status was measured on pre-operative and post-operativeassessment by using the Unified Parkinson Disease Rating Score (UPDRS). The patient was kept admitted 2 days'post-surgery, while stitches were removed on $10^{\text {th }}$ post-operative day. The patient was kept on follow-up on third week and three months to assess the improvement in the patient's status, which was based on UPDRS III scoringsystem ${ }^{[5}$, 10].

\section{Surgical Management:}

Pallidotomy was performed contralateral to the affected side having more pronounced dyskinesia or the tremor and if motor symptoms were seen to be symmetrical, the pallidotomy was done on the side contralateral to the affected hand. One day before the procedure, the antiparkinsonian medications were stopped to make the motor symptoms more prominent. A leksell frame was applied and the patient was sent for a CT scan brain plain with cut slices at $2 \mathrm{~mm}$ intervals through the third ventricle andupper midbrain. The ring was fastened to the patient sucht hat the cuts would be parallel to the intercommissuralplane. After CT scan brain, MRI brain is done with Gamma plan protocol T1 \& T2 and data is introduced to surgiplan laptop where T1 $\& T 2$ images are diffused and the coordinates $X, Y, Z$ of a target were calculated at this level atinter-commissural plane, radiographic targets vary person to person but usually $5 \mathrm{~mm}$ below theinter-commissural plane, $23 \mathrm{~mm}$ lateral to the midline, and $2 \mathrm{~mm}$ anterior to the midpoint of the inter-commissural plane are taken on the radiographic image. The patient is shifted to the operation theatre, lying supine on the table with frame fixed to head holder, under local anesthesia and after aseptic measures, a burr hole was made at the coronal suture level and calculation are adjusted to the frame $X, Y$ and $Z$-axis. The electrode introduced though given safe trajectory.

Experience has allowed us todetermine the threshold for a motor and, occasionally sensoryresponse that indicates that the electrode is too close to thei nternal capsule and needs to be moved to a target moreanterior and lateral. Stimulation was carried out at location 4 and 2 $\mathrm{mm}$ above the target and then on the target, and 1 and $2 \mathrm{~mm}$ past the target to reach a position deep in the pallidum that did not evoke visual or other untowardresponses. The first lesion was made at $80^{\circ} \mathrm{C}$ for $60 \mathrm{~s}$ afternoting that no ill effects occurred from raising the temperature to $100^{\circ} \mathrm{C}$. The response was observed in an awake patient, based on rigidity and tremors second and third lesions weremade at $80^{\circ} \mathrm{C}$ after the electrode was withdrawn $3 \mathrm{~mm}$. While, we did not use intra-operative microelectrode recording in our study, the post-procedure patient was kept in the daycare, anti-epileptics and anti-biotic were given. The effect was seen per operative, post-surgery and at 3 months follow-up.

\section{Statistical Calculations:}

Data was analyzed on SSPS 25. For qualitative data means and standard deviation was calculated and for qualitative data frequency and percentage were calculated. The chi-square tests were applied to see the difference of significance in the stratified groups. Significance of different between groups to compare between the pre-op or post-op treatments, was calculated through non-parametric assessment Kruskal-Wallis tests. A p-value of less than 0.050 was considered the statistically significant.

\section{RESULTS:}

\section{Clinical Information:}

Table-I describes the minimum, maximum and mean values of the parameters. The mean age of the patients was around 57 years, with minimum 41 years and maximum 73 years. There was $34(81 \%)$ male and $8(19 \%)$ female patients. Mean duration of the disease was 6 years, with minimum 5 years and maximum 8 years. Mean of pre-op URPDS-III score without an intake of medication was 78.95, mean of pre op UPDRSIII score with the medication was 46 and the mean of post op UPDRS-III score was 28 . 
Table-I:Clinical Information- Parkinsonian Diseases $(n=42)$.

\begin{tabular}{|c|c|c|}
\hline Parameter & Minimum & Maximum \\
\hline Age (years): Mean $=56.54 \pm 8.43$ & 41 & 73 \\
\hline Duration of Disease (years), Mean $=6.166 \pm 1.03$ & 5 & 8 \\
\hline Pre op UPDRS-III (off med), Mean $=78.952 \pm 11.08$ & 63 & 101 \\
\hline Pre op UPDRS-III (on med), Mean $=46.023 \pm 4.15$ & 39 & 55 \\
\hline Post op UPDRS-III (off med), Mean $=28.428 \pm 2.51$ & 23 & 35 \\
\hline \multirow{2}{*}{ Pallidotomy } & Left Side & Right Side \\
\hline & $21(50 \%)$ & $21(50 \%)$ \\
\hline \multirow[t]{2}{*}{ Gender } & Male & Female \\
\hline & $34(81 \%)$ & $8(19 \%)$ \\
\hline
\end{tabular}

\section{Stratification of Left/Right Side Proportions in Age Groups and Gender:}

Table-II shows the stratification of left and right sided proportions in age groups (less than 45 years $\&$ greater than 45 years) and gender distribution. Maximum number of patients $(n=19)$ who were more than 45 years, were having left sided proportion. More male patients $(n=18)$ were having left sided proportion as compared to female patients. These groups were not significantly different ( $p$ values: $0.377,0.154)$.

Table-II: Stratification of Left/Right Side Proportions in Age Groups and Gender.

\begin{tabular}{|c|c|c|c|c|c|}
\hline Variables & $\mathbf{n}$ & $\begin{array}{c}\text { Left Side } \\
\text { (Proportion) }\end{array}$ & $\begin{array}{c}\text { Right Side } \\
\text { (Proportion) }\end{array}$ & p-Value & Chi-Square \\
\hline \multicolumn{7}{|c|}{ Age } \\
\hline >45 year & 36 & 19 & 17 & $\begin{array}{c}0.377 \\
\text { (insignificant) }\end{array}$ & 0.7778 \\
\hline >45 year & 6 & 2 & 4 & \multirow{2}{*}{$\begin{array}{c}0.154 \\
\text { (insignificant) }\end{array}$} & 2.027 \\
\hline Male & 34 & 18 & 16 & 6 & \\
\hline
\end{tabular}

\section{Stratification of Left/Right Side Proportions Symptoms and Complication:}

Table-III shows the stratification of left and right sided proportions related to primary symptoms and complications. Majorityof patients (57.5\%)were having dyskinesia as primary symptom. Dyskinesia was reported in 23 patients and among them, 13 were having left sided proportion. 40\% of patients reported motor fluctuation as primary symptom. Almost equal distribution of left/right side involvement was found with motor fluctuation. Only two patients reported tremors as primary symptom. Majority ( $88 \%$ ) of patients did not report any complication. These groups (complications) were not significantly different ( $p$-value: 0.633 ) 
Table-III: Stratification of Left/Right Side Proportions Symptoms and Complication

\begin{tabular}{|c|c|c|c|c|c|}
\hline Variables & N (\%) & $\begin{array}{c}\text { Left Side } \\
\text { (Proportion) }\end{array}$ & $\begin{array}{c}\text { Right Side } \\
\text { (Proportion) }\end{array}$ & p-Value & Chi-Square \\
\hline \multicolumn{6}{|c|}{ Complications } \\
\hline Yes & $5(12)$ & 3 & 2 & 0.633 & 0.227 \\
\hline No & $37(88)$ & 18 & 19 & (insignificant) & \\
\hline
\end{tabular}

\section{Kruskal-Wallis Test:}

According to the Kruskal-Wallis test, a significant difference $(p<0.001)$ existed in pre \& postoperative UPDRS-III scores (Table-IV). A significant difference $(p<0.001)$ also existed between on $\&$ off medications UPDRS- III (pre-op/post-op) scores.

Table-IV: Kruskal-Wallis Test.

\begin{tabular}{|c|c|c|}
\hline Groups & H-value & p-Value \\
\hline $\begin{array}{c}\text { UPDRS III-pre op (off_Med) \& } \\
\text { UPDRS III-post op (Pallidotomy) (off_Med) }\end{array}$ & 62.2588 & $<0.001^{*}$ \\
\hline $\begin{array}{c}\text { UPDRS III-pre op (on_Med) \& } \\
\text { UPDR III-post op (Pallidotomy) (off_Med) }\end{array}$ & 62.2588 & $<0.001^{*}$ \\
\hline UPDRS III-preop (off_Med), & 111.1181 & $<0.001^{*}$ \\
\hline
\end{tabular}

*highly significant

Key: Off-Med=No medication; On-Med: With medication; Pre-op: pre operatively; Post op=post operatively

\section{DISCUSSION:}

We conducted a descriptive study to report the effectiveness of Pallidotomy in parkinsonian disease (PD). We compared the UPDRS-III scores pre and post operatively and also with the intake of medications. We found that a significant difference $(p<0.001)$ existed in pre $\&$ post-operative UPDRS-III scores. A significant difference $(p<0.001)$ also existed between on \& off medications UPDRS- III (pre-op/post-op) scores. Mean of pre-op URPDS-III score without an intake of medication was 78.95, mean of pre op UPDRS-III score with the medication was 46 and the mean of post op UPDRS-III score was 28 . We can see that the UPDRS-III score decreased considerably with the Pallidotomy.

Majority of our patients $(57.5 \%)$ were having dyskinesia as primary symptom. $40 \%$ of patients reported motor fluctuation as primary symptom. Almost equal distribution of left/right side involvement was found with motor fluctuation. Only two patients reported tremors as primary symptom. Majority (88\%) of patients did not report any complication.

Ball $\mathrm{N}^{[11]}$ in their study has found multiple environmental factors including heavy metal exposure, diet habits, pesticide toxicity, high magnetic field areas, smoking, water supply. while in our study patients were usually aged and no cause of exposure was found, mostly it was idiopathic while in other

Almost all patients had improvement intheir symptoms and a decrease in medication dose, some with minimal to moderate complication. The pallidotomy significantly improves the symptoms and improved the daily life activities of the patient as it is seen in many studies that pallidotomy has markedly modified symptoms of Parkinson's disease like dyskinesia, rigidity and tremor [12, 13, ${ }^{14]}$.From the experience through multiple studies, it is gained that bilateral pallidotomy can have negative impact like swallowing, speech and cognition defect which can lead to depression ${ }^{[15] . T h e r e f o r e, ~ w e ~ p e r f o r m e d ~ a l l ~ o u r ~ c a s e s ~}$ 
unilaterally, to get over such complications.

Keep close observation, studies have shown that overall, $25 \%$ to $35 \%$ percent reduction is seen in UPDRS III motor score in the duration of 6 months clinical follow-up [13]. Gender difference is also observed in PD, overall males are 1.52 times more affected compared to females. Depending on lifestyle, regional location and maybe hormonal factors have their role along with different risk factors in PD ${ }^{[16]}$.In comparison to our study which had male dominance in terms of patients.

Studies have shown that hemorrhageisthe most common complication, current study showed $9.5 \%$ while $21 \%$ being the highest ${ }^{[17]}$ of all procedures such complication was not seen in our study. The Gait difficulties and postural instability with PD progression, get worse and to a certain point may become resistant to treatment, which can have impact on the quality of life. So along with pharmacological and lesioning and stimulations,adapted physical activities and rehabilitation play important role in improvement of the patient ${ }^{[18]}$.

Some thought of school argues that pallidotomy is old-fashioned so be abandonedas functional neurosurgery has progressed more towards deep brain stimulation which is safer andcan be done bilaterally plus it is reversible, but some argue that pallidotomy is cost-effective with shorter follow up and evidence-based medicine also show that unilateral pallidotomyis still better for patients with advanced $P D^{[19]}$.

Ourpatients had reduced medication to half and adjusted the dose accordingly of dopaminergic medications by the neurologist. It is worth mentioning that lesioning procedure is costeffective for the patients. For a patient who cannot keep up with follow up or financial constraints, lesioningis a viable option. The limitation of the study is we had short duration of follow up and small number of a patient, we recommend that such study must be conducted at larger scale to help the people in minimizing their sufferings, which in future may need a larger study involving many centers.

\section{CONCLUSION:}

The result of pallidotomy is promising especially for unilateral pallidotomy to minimize the risk of cognition and speech disorder. Currently, pallidotomy is associated with minimal complications, more effective and improved the quality of life of Parkinsonian patientsas well as cost-effective.

ACKNOWLEDGEMENT: None CONFLICT OF INTEREST: None GRANT SUPPORT \& FINANCIAL DISCLOSURE: None

\section{REFERENCES:}

1. Fu YS, Cheng YC, Lin MY, Cheng $H$, Chu PM, Chou SC, et al. Conversion of human umbilical cord mesenchymal stem cells in Wharton's jelly to dopaminergic neurons in vitro: potential therapeutic application for Parkinsonism. Stem cells. 2006;24(1):115124.Doi: 10.1634/stemcells.2005-0053

2. Bouyer B, Scemama C, Roussouly P, Laouissat $F$, Obeid I, Boissière $L$, et al. Evolution and complications after surgery for spine deformation in patients with Parkinson's disease. Orthopaedics \& Traumatology: Surgery \& Research. 2017;103(4):517-522. Doi: $10.1016 /$ j.otsr.2016.12.024

3. Tysnes OB, Storstein A. Epidemiology of Parkinson's disease. Journal of Neural Transmission. 2017;124(8):901-905.Doi. org/10.1007/s00702-017-1686-y

4. Marras C, Beck JC, Bower JH, Roberts E, Ritz B, Ross GW, et al. Prevalence of Parkinson's disease across North America. NPJ Parkinson's Disease. 2018;4(1):1-7. Doi: 10.1038/ s41531-018-0058-0

5. Tyurnikov VM, Nizametdinova DM, Gushcha AO, Fedotova EY, Poleshchuk VV, Timerbaeva $\mathrm{SL}$, et al.Unilateral Posteroventral Pallidotomy in the Treatment of Drug-Induced Dyskinesia in Parkinson's Disease. Zhurnal Voprosy NeirokhirurgiiImeni NN Burdenko. 2017;81(5):69-75.

6. Moosa $S$, Martínez-Fernández $R$, Elias WJ, Del Alamo M, Eisenberg HM, Fishman PS. The role of high-intensity focused ultrasound as a symptomatic treatment for Parkinson's disease. Movement Disorders. 2019;34(9):1243-1251.Doi: 10.1002/ 
mds. 27779

7. Rotter J, Cosgrove GR. Parkinson's Disease: Lesions. In Stereotactic and Functional Neurosurgery. Springer, Cham. 2020: 271287. Doi: $10.1007 / 978-3-030-34906-6 \_19$

8. Munhoz RP, Cerasa A, Okun MS. Surgical treatment of dyskinesia in Parkinson's disease. Frontiers in Neurology. 2014;5:65. Doi./10.3389/fneur.2014.00065.

9. Martínez-Moreno NE, Sahgal A, De Salles A, Hayashi M, Levivier M, Ma L, et al. Stereotactic radiosurgery for tremor: systematic review: International Stereotactic Radiosurgery Society Practice Guidelines. Journal of Neurosurgery.2018;130(2):589-600.Doi: $10.3389 /$ fneur.2014.00065

10. Samuel M, Caputo E, Brooks DJ, Schrag A, Scaravilli T, Branston NM, et al. A study of medial pallidotomy for Parkinson's disease: clinical outcome, MRI location and complications. Brain: A Journal of Neurology. 1998;121(1):59-75. Doi: 10.1093/ brain/121.1.59

11. Ball N, Teo WP, Chandra S, Chapman J. Parkinson's disease and the environment. Frontiers in Neurology. 2019;10:218. Doi: 10.3389/fneur.2019.00218

12. Cif L, Hariz M. Seventy years of pallidotomy for movement disorders. Movement Disorders. 2017;32(7):972-982.Doi.org/10.1002/ mds. 27054

13. Krack $P$, Martinez-Fernandez R, Del Alamo M, Obeso JA. Current applications and limitations of surgical treatments for movement disorders. Movement Disorders. 2017;32(1):36-52.Doi. org/10.1002/mds. 26890

14. Homayoun $\mathrm{H}$. Parkinson disease. Annals of Internal Medicine. 2018;169(5):ITC33-48. Doi: $10.7326 /$ AITC201809040.

15. Hamel W, Köppen JA, Hariz M, Krack P, Moll CK. The pioneering and unknown stereotactic approach of Roeder and Orthner from Göttingen. Part I. Surgical technique for tailoring individualized stereotactic lesions. Stereotactic and Functional Neurosurgery. 2016;94(4):240-253.

16. Haaxma CA, Bloem BR, Borm GF, Oyen WJ, Leenders KL, Eshuis $S$, et al. Gender differences in Parkinson's disease.
Journal of Neurology, Neurosurgery \& Psychiatry. 2007;78(8):819-824. Doi: $10.1136 /$ jnnp. 2006.103788

17. Lang $A E$. Surgery for Parkinson disease: a critical evaluation of the state of the art. Archives of Neurology. 2000;57(8):11181125.Doi: 10.1001/archneur.57.8.1118

18. Debû B, Godeiro CD, Lino JC, Moro E. Managing gait, balance, and posture in Parkinson's disease. Current Neurology and Neuroscience Reports. 2018;18(5):1-2.Doi: 10.1007/s11910-018-0828-4

19. Shrestha R, Taira T, Shrestha P, Rajbhandari P, Dhakal S, Acharya S, et al. Result of Pallidotomy in Parkinson's Disease in Nepal. Nepal Journal of Neuroscience. 2016;13(2):68-72. Doi.org/10.3126/njn. v13i2.20479

\section{Author's Contribution:}

Aurangzeb Kalhoro: Proposed topics and basic study design, data collection and statical analysis.

Abdul Basit Sattar: Interpretation of results, literature review, intellectual content.

Abdul Sattar M. Hashim: Analysis of data, study design, methodology and proofreading.

Abid Saleem: Analysis of data, study design and methodology.

Submitted for publication: 19-12-2020

Accepted after revision: 26-04-2021 